\title{
THE PEDAGOGICAL EVALUATION OF THE RESPONSIVENESS OF PRE-SERVICE TEACHERS
}

\author{
Inese Jurgena \\ University of Latvia, Latvia \\ Dagnija Cēdere \\ University of Latvia, Latvia \\ Ingrīda Keviša \\ Latvian Academy of Culture, Latvia
}

\begin{abstract}
With the guidelines for pre-school education coming into effect, a paradigm change has occurred in Latvia, focusing on a child-centred educational process. Contradictions can be observed in the professional training of pre-school teachers. Clearly, pre-school educators ensure the transfer of values to the next generation and the stability of the system of education; nevertheless, their activity is often focused on imparting reproductive knowledge and skills and following familiar algorithms and stereotypes. The innovative trend - the development of child's social and emotional skills - is not always dominant in the work of pre-school teachers. The aim of the research is to analyse the views of students, pre-service teachers, about teacher's responsiveness in pedagogical activity. The research methods include the theoretical method - the analysis of theoretical literature, regulatory documents and academic studies - and the empirical method - surveys. The data have been processed with SPSS program. 247 full-time and part-time students of the University of Latvia participated in the study. The authors of the article concluded that pre-service teachers' understanding of teacher's responsiveness is sufficient. Most students are aware of the importance of teacher's supportive reactions, responsibility and leadership in the regulation of child's emotions. Pre-school teacher training plays an important role in the implementation of the social-emotional learning process, paying particular attention to raising students' awareness of the role of emotions in the development of child's selfregulation and the advancement of teachers' skills in building positive and supportive relationships with children and parents.
\end{abstract}

Keywords: pre-school teacher training, social-emotional skills, teacher's responsiveness.

\section{Introduction}

Globalization and digitalization change professions and the ways of collaboration in society and among individuals, thus leading to the need to acquire a comprehensive set of skills: cognitive, social and emotional skills, as well as job-specific skills. 
Latvia has started a reform in education which involves a transition to competency-based curricula so that students could acquire the skills needed in the 21st century. For this initiative to be successful, it is necessary to upgrade the qualifications of educators, paying special attention to the specific features of the work of pre-school teachers and the development of children's skills at an early stage of their lives. (OECD. Skills Strategy Latvia: Assessment and Recommendations, 2019)

With the national guidelines for education coming into effect, there has taken place a paradigm change in Latvia, focusing on a child-centred pedagogical process (Cabinet of Ministers of the Republic of Latvia. Regulations on National Guidelines for Pre-primary Education and Templates of Pre-primary Education Programs, 2018).

It should be noted, however, that contradictions can be observed in the work of pre-school teachers. There is no doubt that pre-school teachers ensure the transfer of values to the following generation and the stability of the system of education, whereas their pedagogical activity is still focused on imparting reproductive knowledge and skills and following familiar stereotypes and algorithms. The innovative trend - the development of child's social and emotional skills, which includes self-awareness and the management of emotions, thoughts and behaviour, ability to understand oneself and other people as well as to build positive relationships - is not always dominant in the work of pre-school teachers (Ministry of Education and Science of the Republic of Latvia, n.d.).

In this respect, a significant issue is the training of pre-school teachers in the institutions of higher education, with a particular emphasis on the advancement of students' social and emotional skills and their building awareness of the importance of teacher's responsiveness in developing child's self-regulation and positive, supportive relationships with other children and parents.

The aim of the research is to analyse the views of students, pre-service teachers, about the role of teacher's responsiveness in pedagogical activity.

\section{The theoretical basis of the problem}

In order to implement child education and socialization, pre-school teachers have to ensure emotionally secure and supervised environment where child's socially-emotional learning can take place (Denham, Basett, \& Zinsser, 2012).

Studies in pre-school education show that with the growing number of problems in emotional behaviour, comprehensive prevention is needed in the 
pedagogical process, as well as early intervention in order to identify problems in child's behaviour and reduce them (Poulou, Basett, \& Denham, 2018).

Based on the idea that close communication - affectionate and loving relationships between a child and a pre-school teacher, provided they are positive, stimulating and age-appropriate, causes changes in all areas of the child's development (Müller, 2016), the studies concerning teachers' social and emotional abilities, including responsiveness as teacher's reaction to children's emotions, become increasingly topical (Buettner, Jeon, Hur, Rachel, \& Garcia, 2016; Sarah, Chryso, Jeon, Buttner, \& Hur, 2017).

Teacher's ability to recognize, use and manage child's emotions is regarded as the basis for teachers' attitude to children and their ability to ensure a psychologically safe environment (Ahn \& Stoffer, 2006; Harvey, Bimler, Evans, Kirland, \& Pechtel, 2012; Merritt, Wanless, Rimm-Kaufman, Cameron, \& Peugh, 2012; Morris, Denham, Basset, \& Curby, 2013). Several studies highlight the fact that emotionally responsive teachers do their professional work better (Jones, Bouffard, \& Weissbourd, 2013).

However, scholars admit that relatively little is known about the factors that affect pre-school teachers' ability to react appropriately to child's negative emotions and to complicated mutual relationships such as depression (Jeon et al., 2014; Sandilos et al., 2015), stress (Zinsser et al., 2013), emotional exhaustion, the knowledge of the strategies of overcoming stress and their use in resolving pedagogical situations, teacher's special education, etc. (Sarah, Chryso, Jeon, Buettner, \& Hur, 2017; Jeon, Hur, \& Buettner, 2016).

It has been established that teachers' responsiveness in classrooms and their professional commitment are largely influenced by their ability to perform socially and emotionally in classrooms and to provide positive social-emotional capacity, to create warm and supportive teacher-child relationhips, efective and attentive classroom management, emotional responsiveness, and consistent and stable classroom ratines. Researchers point out that teachers' responsiveness and their professional commitment are two key factors concerning the quality of children's general care (Denham et al., 2012; Thomason \& La Paro, 2013).

It has also been established that teachers possessing good social and emotional capabilities more frequently use supporting strategies aimed at overcoming child's negative emotions: emotion-regulation and problem-focused resolution. The use of these strategies for the regulation of child's emotional activity is regarded as the criteria of teacher's responsiveness in the work of preschool teachers (Buettner, Jeon, Hur, Rachel, \& Garcia, 2016), and it is pointed out that teachers must give emotional support to children in their care (Thomason \& La Paro, 2013).

Responsiveness studies have revealed that adults' reactions to children's negative emotions can have significant impact on children's general and 
emotional development and may have far-reaching consequences for behavioural problems in the later stages of child's development (Fabes, Poulin, Eisenberg, \& Madden-Derdich, 2002). Adults' unsupportive reactions, including punishing children, minimizing the significance of child's emotions or displaying discomfort caused by the display of child's emotions affect the development of children's emotional competence.

With regard to our study, it is also important that teacher's reaction, including responsiveness to the complexity of children's mutual relationships, can be the basis for a mechanism by means of which a teacher can resolve problems in child's behaviour, and that teacher's social and emotional capabilities can be developed in the process of pre-school teacher training (Harvey, Evans, Hill, Henricksen, \& Bimler, 2016; Poulou, Bassett, \& Denham, 2018).

In the latest studies concerning the responsiveness of pre-school teachers, several authors (Jeon, Hur, \& Buettner, 2016) have elaborated methodology for studying teacher's responsiveness and have singled out the types of reactions to children's emotions and social interactions.

Still, the views of pre-school teachers about teacher's responsiveness have not been studied so far. Therefore, we focused on the study of this issue.

The institutions of the higher education and the academic staff working in them are known to create the educational environment where the readiness of prospective teachers for their professional activity is being developed. The readiness for professional activity is the aggregate of qualities including the result of acquired positive experience and the successful inner potential of pedagogical activity, as well as the condition of resources for purposeful activity (Baltušîte, 2012). Therefore, it is important to study students' opinions in order to understand the attitude of pre-service teachers to the role of teacher's responsiveness in pedagogical activity.

\section{Methodology}

The participants of the study were 247 students of the University of Latvia - pre-service pre-school teachers. $20 \%$ of the sample were full-time students and $80 \%$ part-time students. $68 \%$ of the respondents were first-year students and $32 \%$ second-year students. All the respondents were women. The age of the respondents ranges from 17 to 54 years.

There was used a questionnaire for the study of the responsiveness of preschool teachers elaborated by L. Jeon, E. Hur, and C. Buettner (2016). The questionnaire includes five different situations causing children's negative emotions with potential responses according to a 7-point scale (1 - very unlikely, 
7 - very likely). Respondents' answers were coded according to five strategies of teacher's responsiveness:

- $\quad$ PR - punitive reactions

- $\quad$ EE - expressive encouragement

- $\quad$ EFR - emotion-focused reactions

- $\quad$ PFR - problem-focused reactions

- $\quad$ MR - minimization reactions

The reliability (inter-item consistency) of the questionnaire according to Cronbach's alpha coefficient was .76.

A non-parametric test was performed, and Spearman's correlation coefficient was used in order to identify the strength between variables. The Mann-Whitney U test was used to compare two independent groups, and the Kruskal-Wallis Test - to compare several independent groups. In order to determine the key factors, the principal component analysis with varimax rotation was applied. The obtained qualitative data were processed with the SPSS program.

\section{Results and Discussion}

The answers provided by the respondents give a general insight in the views of prospective pre-school teachers how to handle situations caused by children's negative emotions. The respondents' answers concerning five model situations were grouped according to five types of teacher's strategies (Table 1).

Table 1 The mean values of respondents' answers in accordance with the types of strategies $(N=247)$

\begin{tabular}{|c|c|c|c|c|}
\hline Types of strategies & Mean & SD & Median & Cronbach’s alpha \\
\hline PR & 1.66 & .72 & 1.40 & .55 \\
\hline EE & 4.32 & 1.24 & 4.40 & .64 \\
\hline EFR & 6.03 & .74 & 6.00 & .74 \\
\hline PFR & 6.14 & .72 & 6.20 & .60 \\
\hline MR & 2.69 & .81 & 2.60 & .66 \\
\hline
\end{tabular}

According to the responses of the surveyed students, pre-service pre-school teachers do not support punitive reactions (PR), the evidence of which is the distinctly low mean value $(M=1.66)$. A high mean value refers to the strategy of emotionally focused reaction EFR $(M=6.03)$, which implies that the students appreciate teacher's reaction aimed at comforting the child. In all the situations, respondents also highly appreciated teacher's strategy aimed at solving the problem together (PFR, $M=6.14$ ). 
Students' responses show that the paradigm change taking place in the Latvian system of education and focusing on a child-centred pedagogical process marks the strengthening of human values. The ability to correctly regulate, perceive, understand and use emotions can me important in all cultures, but what makes emotional behaviour appropriate will partly depend on people's common values and beliefs (Poulou, Bassett, \& Denham, 2018).

The respondents have mixed attitude to choosing the strategy that encourages children to express their emotions openly, e.g., "it is okay to be sad" (EE, $M=4.32$ ). The need to minimize the seriousness of the child's problem, e.g., by telling the child that he/she is overreacting, has also been given low ratings by pre-service teachers (MR, $M=2.69$ ).

The students' responses indicate that they partially understand the importance of the verbal techniques of emotion regulation in forming child's active contact with the attachment person to obtain information on how the child should feel and behave (Klinnert, Campos, Sorce, Emde, \& Svedja, 1983). Thus, it can be concluded that the students do not fully appreciate children's seeking for support and its availability as an important resource for coping with insecurity. The students also do not realize that this seeking and the way how children look for support are closely related to their attachment experience in early childhood.

When conducting the correlation analysis (Table 2), a close correlation can be seen between the strategies EFR and PFR $\left(r_{s}=.58\right)$, which implies that the strategies focused on comforting the child and resolving the problem are perceived by the students as the most important ones and as equally important. On the other hand, the high correlation between the strategy PR and MR $\left(r_{s}=.50\right)$ requires further study.

Table 2 Bivariate correlations between the strategy subscales

\begin{tabular}{|c|c|c|c|c|c|}
\hline & PR & EE & EFR & PFR & MR \\
\hline PR & 1 & & & & \\
\hline EE & .05 & 1 & & & \\
\hline EFR & .01 & $.19^{* *}$ & 1 & & \\
\hline PFR & -.06 & $.34^{* *}$ & $.58^{* *}$ & 1 & \\
\hline MR & $.50^{* *}$ & $.17^{* *}$ & $.24^{* *}$ & $.16^{*}$ & 1 \\
\hline
\end{tabular}

**. Correlation is significant at the 0.01 level (2-tailed).

*. Correlation is significant at the 0.05 level (2-tailed).

To get a better insight how pre-service teachers understand the choice of a strategy, there was conducted a factor analysis. The KMO measure of sampling adequacy was 0.81, and Bartlett's test of sphericity was significant $\left(c^{2}(247)=\right.$ 1659.50, $p<.001$ ). Thus, the data were meaningful and compatible to perform 
the factor analysis. The principal component analysis was performed using the extraction method with the succeeding rotation of varimax with Kaiser normalization. The items with the factor loading no less than 0.50 were subjected to the analysis. Parallel analysis was used to determine the number of principal components retainable for the factor analysis. As a result, there were determined three principal factors, which account for $45 \%$ of the variance (Table 3).

Table 3 Results of principal component analysis with children's negative emotions scale

\begin{tabular}{|c|c|c|c|c|c|c|}
\hline \multirow{2}{*}{ Items } & \multirow{2}{*}{ Mean } & \multirow[t]{2}{*}{$S D$} & \multirow{2}{*}{$\begin{array}{l}\text { Sub- } \\
\text { scale }\end{array}$} & \multicolumn{3}{|c|}{$\begin{array}{c}\text { Rotated factor } \\
\text { load values }\end{array}$} \\
\hline & & & & F1 & F2 & F3 \\
\hline $\begin{array}{l}\text { 5c. Try to make the child feel better by talking about } \\
\text { fun things }\end{array}$ & 6.11 & 1.02 & $\begin{array}{l}\mathrm{EF} \\
\mathrm{R}\end{array}$ & .66 & & \\
\hline 5a. Help the child think of constructive things to do & 6.07 & 1.09 & PFR & .66 & & \\
\hline $\begin{array}{l}\text { 3a. Comfort the child and try to make him/her feel } \\
\text { better }\end{array}$ & 6.36 & 1.02 & $\begin{array}{c}\mathrm{EF} \\
\mathrm{R}\end{array}$ & .61 & & \\
\hline $\begin{array}{l}\text { 4c. Suggest an activity that would attract his/her } \\
\text { attention }\end{array}$ & 6.31 & .92 & $\begin{array}{c}\mathrm{EF} \\
\mathrm{R}\end{array}$ & .57 & & \\
\hline 2c. Help the child figure out how to fix the toy & 6.30 & .99 & PFR & .54 & & \\
\hline $\begin{array}{l}\text { 3e. Tell the child that I'll help him/her practice so that } \\
\text { he/she can do better next time }\end{array}$ & 6.49 & .78 & PFR & .53 & & \\
\hline $\begin{array}{l}\text { 1e. Soothe the child and do something fun with him/her } \\
\text { so that the child would not feed so sad }\end{array}$ & 6.17 & 1.17 & EFR & .51 & & \\
\hline $\begin{array}{l}\text { 2e. Tell the child to stop crying, or he/she will not be } \\
\text { allowed to play with this toy anytime soon }\end{array}$ & 1.26 & .76 & PR & & .77 & \\
\hline 3b. Tell the child that he/she is over-reacting & 1.85 & 1.24 & MR & & .69 & \\
\hline $\begin{array}{l}\text { 3c. Tell the child to straighten up or he/she will have to } \\
\text { sit out for a while }\end{array}$ & 1.59 & 1.06 & PR & & .68 & \\
\hline $\begin{array}{l}\text { 4a. Tell the child that, if he/she starts crying, he/she } \\
\text { will have to sit out for a while. }\end{array}$ & 1.35 & .91 & PR & & .67 & \\
\hline 5e. Tell the child he/she is acting like a baby & 1.17 & .61 & MR & & 63 & \\
\hline $\begin{array}{l}5 \mathrm{~d} \text {. Tell the child that he/she must stay nearby and } \\
\text { interact with visitors appropriately }\end{array}$ & 2.45 & 1.58 & PR & & .59 & \\
\hline 2b. Tell the child that he/she is overreacting & 1.67 & 1.16 & MR & & .55 & \\
\hline 4b. Tell the child it's OK to cry if he/she feels bad & 3.63 & 1.88 & $\mathrm{EE}$ & & & .78 \\
\hline 2d. Tell the child it's OK to cry & 4.39 & 1.90 & $\mathrm{EE}$ & & & .76 \\
\hline 5b. Tell the child that it is OK to feel nervous & 5.17 & 1.58 & $\mathrm{EE}$ & & & .65 \\
\hline $\begin{array}{l}\text { 1d. Encourage the child to express his/her feelings of } \\
\text { anger and frustration }\end{array}$ & 2.98 & 1.87 & $\mathrm{EE}$ & & & .60 \\
\hline 3d. Encourage the child to talk about his/her feelings & 5.44 & 1.16 & EI & & & .59 \\
\hline $\begin{array}{l}\text { \% of variance explained } \\
\text { Eigenvalues } \\
\text { Cronbach’s alpha }\end{array}$ & & & & $\begin{array}{c}19 \\
6.26 \\
.75 \\
\end{array}$ & $\begin{array}{c}16 \\
1.62 \\
.77 \\
\end{array}$ & $\begin{array}{c}10 \\
4.32 \\
.74\end{array}$ \\
\hline Total variance explained: $45 \%$ & & & & & & \\
\hline
\end{tabular}


The factor analysis shows a close correlation between the strategy subscales EFR and PFR, which constitute one strategy group (Factor F1). It can be inferred that the students put equal value on emotionally focused reactions and on problem focused reactions. There is no fundamental difference between the students' attitude to punitive reactions (PR) and minimization reactions (MR), which constitute one common strategy group (Factor F2). Thus, the significance of comforting a child is undervalued, the minimization of the problem, e.g., telling a child that he/she is overreacting, is not regarded as a good strategy ( $2 \mathrm{~b}, M=1.67$ ). The third factor (F3), which corresponds to teacher's encouragement for children to express their negative emotions openly (EE), is characterised by medium-high averages, which implies that the surveyed pre-service teachers undervalue this strategy.

By means of Mann-Whitney $U$ test, it was established that there are no statistically significant differences between the opinions of full-time and parttime students.

To compare students' opinions in accordance with their age, ranging from 17 to 54 years, the respondents were divided into four age-groups: 17-20 years (Group A), 21-30 years (Group B), 31-40 years (Group C) and 41-54 years (Group D). The comparison was done by using the Kruskal-Wallis test. In most cases, the choice of the strategy does not depend on respondent's age. Nevertheless, there are statistically significant differences regarding teacher's reactions of expressive encouragement (Table 4). It appears that the highest mean values correspond to Group C. Thus, the respondents aged 31-40 years are more supportive of teacher's strategy encouraging children to express their negative emotions and validate children's negative emotional states, whereas the mean values corresponding to younger students (Group A) are the lowest.

Table 4 The choice of teacher's strategy depending on respondents' age-group

\begin{tabular}{|c|c|c|c|c|c|c|c|c|}
\hline \multirow{2}{*}{ Item } & \multirow{2}{*}{$\begin{array}{c}\text { Strategy } \\
\text { subscale }\end{array}$} & $\begin{array}{c}\text { Group A } \\
(n=66)\end{array}$ & $\begin{array}{c}\text { Group B } \\
(n=79)\end{array}$ & $\begin{array}{c}\text { Group C } \\
(n=71)\end{array}$ & $\begin{array}{c}\text { Group D } \\
(n=31)\end{array}$ & $\begin{array}{c}\text { Chi- } \\
\text { Square }\end{array}$ & $d f$ & $p$ \\
\hline 1d & EE & $2.41(1.63)$ & $2.90(1.75)$ & $3.46(2.01)$ & $3.26(2.05)$ & 10.72 & 3 & .013 \\
\hline 2d & EE & $4.06(1.82)$ & $4.15(1.85)$ & $5.06(1.87)$ & $4.16(1.99)$ & 13.53 & 3 & .004 \\
\hline 4b & EE & $3.20(1.73)$ & $3.35(1.77)$ & $4.32(1.96)$ & $3.65(1.92)$ & 13.80 & 3 & .003 \\
\hline 5b & EE & $4.70(1.67)$ & $5.22(1.49)$ & $5.54(1.39)$ & $5.26(1.83)$ & 10.09 & 3 & .018 \\
\hline
\end{tabular}

These results imply that the understanding of pre-service teachers as well as their awareness of what their responsiveness as a reaction to children's negative emotions could be comes with experience and self-experience. Selfexperience is the component of consciousness that creates new values in the 
integrated process of perception, understanding and experiencing of facts, objects and processes and influences human behaviour in the present and in the future. New (secondary) self-experience does not exist alongside previous (primary) self-experience, but interacts with it (Giese, 2010, 87). The selfexperience of students already working at pre-school educational institutions (a large proportion of full-time and part-time students), conducting classes and developing children's social and emotional skills represents their knowledge, skills and attitudes obtained during their life activity that have become personally significant values.

\section{Conclusion}

The professional preparedness of prospective pre-school teachers is formed in the educational environment of the institution of higher education by accumulating positive pedagogical experience and actively participating in the evaluation of changing and multi-dimensional educational processes. Therefore, it is important to study students' opinions in order to understand students' perceptions concerning the role of teacher's responsiveness in pedagogical activity.

Having analysed the data of the survey conducted among pre-school teachers, full-time and part-time students of the University of Latvia, the authors concluded that pre-service pre-school teachers have adequate understanding of the importance of teacher's responsiveness, and most students are aware of the role of teacher's supportive reactions, responsibility and guidance in the regulation of children's emotions.

\section{References}

Ahn, H.J., \& Stiffer, C. (2006). Child-care teachers' response to children's emotional expression. Early Education \& Development, 17(2), 253-270.

Baltušite, R. (2012). The Pedagogy Students Readiness for Professional Activities in the School Environment (Synopsis of the Doctoral Thesis), Latvia University of Agriculture, Jelgava. Pieejams https://lufb.llu.lv/dissertation-summary/pedagogics/ Regiina_Baltusiite_promoc_darba_kopsavilkums_2013_LLU_TF_IMI.pdf

Buettner, C.K., Jeon, L., Hur, E., Rachel, E., \& Garcia, C. (2016). Teachers' SocialEmotional Capacity: Factors Associated with Teachers' Responsiveness and Professional Commitment. Early Education and Development, 27(7), 1018-1039.

Cabinet of Ministers of the Republic of Latvia. (2018). Noteikumi par valsts pirmsskolas izglìtības vadlīnijām un pirmsskolas izglìtības programmu paraugiem [Regulations on National Guidelines for Pre-primary Education and Templates of Pre-primary Education Programs]. Rīga: Latvijas Vēstnesis, 236, 30.11.2018., Retrieved from https://likumi.lv/ta/id/303371 
Denham, S.A., Basett, H.H., \& Zinsser, K. (2012). Early Childhood Teachers as Socializers of Young Children's Emotional Competence. Early Childhood Education Journal, 40(3), 137-143.

Fabes, R.A., Poulin, R.E., Eisenberg, N., \& Madden-Derdich, D.A. (2002). The coping with Children's Negative Emotions Scale (CCNS): Psychometric properties and relations with children's emotional competence. Marriage \& Family Review, 34(3-4), 285-310.

Giese, M. (2010). Der Erfahrungsbegriff in der Didaktik- eine semiotishe Analyse. Zeitschrift für Pädagogik, D 7484, Jan./Feb.

Harvey, S.T., Bimler, D., Evans, I.M., Kirland, J., \& Pechtel, P. (2012). Mapping the classroom emotional environment. Teaching and Teacher Education, 28, 628-640.

Harvey, S.T., Evans, I.M., Hill, R.V.J., Henricksen, A., \& Bimler, D. (2016). Warming the emotional climate of the classroom: Can teachers' social-emotional skills change? The International Journal of Emotional Education, 8(2), 70-87.

Jeon, L., Buettner, C. K., \& Snyder, A. R. (2014). Pathways from teacher depression and child-care quality to child behavioral problems. Journal of Consulting and Clinical Psychology, 82(2), 225-235.

Jeon, L., Hur, E., \& Buettner, C.K. (2016). Child-care chaos and teacher's responsiveness: The indirect associations through teacher's emotion regulation and coping. Journal of School Psychology, Volume 59, 83-96.

Jones, S.M., Bouffard, S.M., \& Weissbourd, R. (2013). Educators social and emotional skills vital to learning, Phi Delta Kappan, 94(8), 62-65. DOI: https://doi.org/10.1177/003172171309400815

Klinnert, M.D., Campos, J.J., Sorce, J.F., Emde, R.N., \& Svedja, M. (1983). Emotions as behavior regulators: Social referencing in infancy. In: R. Plutchnik, H. Kellermann (Eds.), Emotion. Theory, research and experience, Vol.2. Emotions in early development (pp. 57-86). San Diego: Academic Press.

Merritt, E.G., Wanless, S.B., Rimm-Kaufman, S.E., Cameron, C., \& Peugh, J. (2012). The contribution of teacher's emotional support to children's social behaviors and selfregulatory skills in first grade. School Psychology Review, 41(2), 141-159.

Ministry of Education and Science of the Republic of Latvia. (n.d.). Skola 2030 [School 2030]. Retrieved from www.skola2030.lv/lv

Morris, C.A.S., Denham, S.A., Bassett, H.H., \& Curby, T.W. (2013). Relations among teachers' emotion, socialization, beliefs and practices and preschoolers' emotional competence. Early Education \& Development, 24(7), 979-999.

Müller, M. (2016). Wertschätzende Kommunikation in der Grundschule: Ein Erlebnis und Sprach orientiertes Handbuch in neuen Modulen Taschenbuch. Createspace Independent Publishing Platform.

OECD. (2019). OECD Skills Strategy Latvia: Assessment and Recommendations. DOI: https://doi.org/10.1787/74fe3bf8-en

Poulou, M.S., Basett, H.H., \& Denham S.A. (2018). Teachers' Perceptions of Emotional Intelligence and Social-Emotional Learning: Students' Emotional and Behavioral Difficulties in U.S. and Greek Preschool Classrooms. Journal of Research in Childhood Education, 32(3), 363-377.

Sandilos, L.E., Cycyk, L.M., Scheffner, H.C., Sawyer, B.E., Lopez, L., \& Blair, C. (2015). Depression, control and climate: An examination of factors impacting teaching quality in preschool classrooms. Early Education \& Development, 26(8), 1111-1127. 
Proceedings of the International Scientific Conference. Volume I, May $22^{\text {th }}-23^{\text {th }}, 2020.276-286$

Sarah, L., Chryso, M., Jeon, L., Buettner C., \& Hur, E. (2017). Preschool Teachers' Professional Training, Observational Feedback, Child-Centred Beliefs and Motivation: Direct and Indirect Associations with Social and Emotional Responsiveness. Child and Youth Care Forum, 46(1), 69-90.

Thomason, A. C., \& La Paro, K. M. (2013). Teachers' commitment to the field and teacherchild interactions in center based childcare for toddlers and three-year-olds. Early Childhood Education Journal, 41(3), 227-234.

Zinsser, K.M., Bailey, C.S., Curby, T.N., Denham, S.A., \& Bassett, H.H. (2013). Exploring the predictable classroom: preschool teacher stress, emotional supportiveness and students' social emotional behavior in private and head start classrooms. NHSA Dialog, 16(2), 90-108. 